
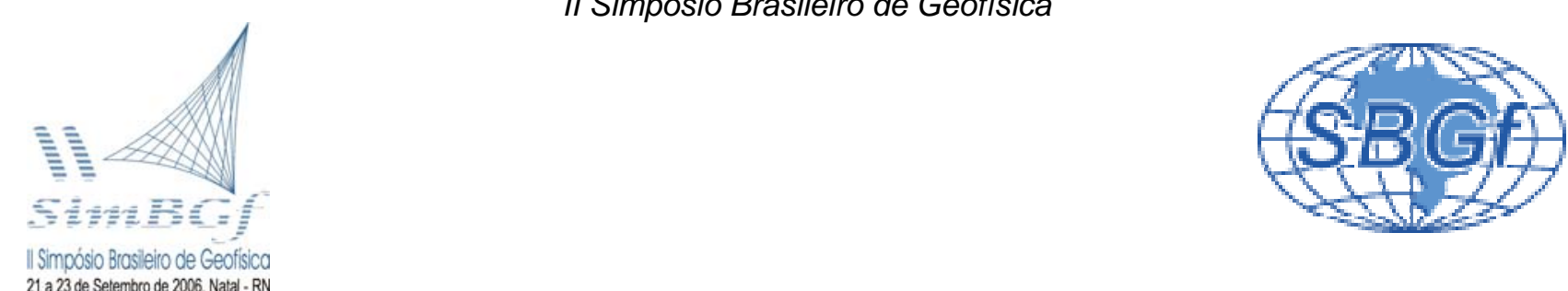

\title{
Crustal seismic anisotropy in NE Brazil
}

Aderson F. do Nascimento, (DFTE/PPGG/UFRN), Mario K. Takeya (DFTE/PPGG/UFRN), Francisco H. R. Bezerra (DG/PPGG/UFRN), Robert G. Pearce (CTBTO)

Copyright 2006, SBGf - Sociedade Brasileira de Geofísica

Este texto foi preparado para a apresentação no Il Simpósio Brasileiro de Geofísica da Sociedade Brasileira de Geofísica, Natal, 21-23 de setembro de 20064. Seu conteúdo foi revisado pela Comissão Tecno-científica do II SimBGf mas não necessariamente representa a opinião da SBGf ou de seus associados. E proibida a reprodução total ou parcial deste material para propósitos comerciais sem prévia autorização da SBG

\section{Abstract}

Some authors have interpreted the seismic anisotropy in NE Brazil and elsewhere in terms of extensive dilatancy anisotropy (EDA), based on the stress field orientation and on the assumption that the pore fluid pressure in the region is high enough to modify microcrack distribution and cause $\mathrm{S}$ wave polarization to become parallel to the north-south oriented minimum horizontal stress $\mathrm{SH}_{\max }$. In the present paper, we will sumarize results from shearwave observations at two sites in NE Brazil: João Câmara and Açu Dam. At each of these location temporary local 3-component eight-station seismograph networks where deployed during the 90's. In both areas, the digital records acquired show remarkably simple seismograms and hypocentral error locations tipically less than $200 \mathrm{~m}$ in a structure of near-uniform wave speed. Both at Açu and João Câmara, the pattern of polarisation of the fastest split shear-wave is consistent with the trend of Precambrian foliation observed in the field, side-looking airborne radar imagery and modelling of waves in the crust. Our results indicate that the EDA or high pore fluid pressure in the region have minor effects in the seismic anisotropy observed.

\section{Introduction}

Seismic anisotropy in the earth's crust has been commonly associated with stress alignement with fluidfilled cracks, known as extensive dilatncy anisotropy (EDA) (Crampin, 1987; Crampin and Lovell, 1991). Crampin and Lovell, 1991]. These fluid-filled cracks are anisotropic to seismic wave propagation, which results in the splitting of two orthogonal shear waves traveling at different velocities. Since fluid-filled cracks will preferentially align parallel to the maximum horizontal stress $\left(\mathrm{SH}_{\max }\right)$, they will remain preferentially open. Thus EDA predicts that the polarization of the faster split shear wave is parallel to $\mathrm{SH}_{\text {max }}$. This agreement between direction of the fastest split shear-wave $\mathrm{SH}_{\max }$ is observed in many parts of the world [see for instance Crampin and Lovell, 1991; Cassidy and Bostock, 1996]. [3] Additionally, in the light of EDA, the direction of the fast shear wave splitting, changes when the pore fluid pressure is high enough to modify the microcrack distributions [Crampin and Zatsepin, 1997]. In that case, shear wave polarizations become parallel to the direction of minimum horizontal stress $\left(\mathrm{SH}_{\min }\right)$, known as $90^{\circ}$ flips. These flips have already been observed in calibrated seismic reflection surveys [Angerer et al., 2002] and in earthquake data too [Crampin et al., 2002]. However, some authors have claimed rock fabric may play a important role in the cause of the observed seismic anisotropy in the crust [Savage et al., 1990; Gledhill, 1991]. In particular, they reported cases in which the direction of the split shear wave polarization is parallel to the tectonic fabric. Brocher and Christensen [1990], for example, suggested that anisotropy due to preferred mineral alignment occurs in the continental crust and may be a more significant mechanism for producing seismic anisotropy than vertical fluid-filled cracks. In the present paper we present data from two sites in NE Brazil: João Câmara and Açu dam areas (Figure 1). Here we combine the fastest shear-wave directions with side-looking airborne radar (SLAR) imagery (when available), and field measurements to investigate the role of the ductile Precambrian fabric in the observed seismic anisotropy. In both sites the direction of the fastest split shear-wave is parallel to the tectonic of "palaeostrain" as a cause of the observed shear-wave anisotropy.

\section{Tectonic/Geological setting}

Both study areas are located on the eastern continental margin of the South American plate. Both regions lie in the Precambrian (>540 Ma) crystalline basement approaching a Cretaceous-Cenozoic (120-20 Ma) sedimentary basin. Pliocene to Quaternary fluvial, aeolian, and coastal sediments occur along the coast. The crystalline basement is composed of the Caicó (predominantly gneisses and mig-matites) and the Seridó groups (predominantly mica-schists, marbles, and quartzites) (Figure 1). The present-day stress field, mainly derived from focal mechanisms, is well known in the region. The composite focal mechanism in the João Câmara area and Açu dam area indicate that the $\mathrm{SH}_{\max }$ is east-west oriented [Ferreira et al., 1998; do Nascimento et al. 2004]. The stress axes derived from the focal mechanisms in both areas indicate a subhorizontal, eastwest trending compression ( $\mathrm{P}$ axis) and a subhorizontal, north-south trending extension ( $T$ axis).

\section{Methodology: event location, alignement measurement and shear-wave analysis}

In João Câmara event locations were made with a twolayer model, consisting of an upper layer of $4.0 \mathrm{~km}$ thickness with $P$ wave speed of $5.90 \mathrm{~km} / \mathrm{s}$, above a halfspace with $P$ wave velocity of $6.10 \mathrm{~km} / \mathrm{s}$ [Takeya, 1992]. In the Açu dam area, the velocity model adopted during the present study assumes an isotropic, homogeneous, infinite half-space with constant $V_{P}$ and $V_{S}$ values. For the Açu dam area, $V_{P} / V_{S}=1.71$ and $V_{P}=6.0 \mathrm{~km} \mathrm{~s}^{-1}$. Details of how these values were found by do Nascimento et al. [2002, 2004]. The choice of this very simple velocity model was based on the local geological setting, where a Precambrian crystalline basement with very simple 
velocity structure exhibits high rigidity and very low attenuation even in the near surface, which is evidenced by the simple nature of the seismograms (very impulsive $P$ and $S$ wave arrivals). All hypocentral locations in both areas were done using the HYPO71 program [Lee and Lahr, 1975].

In the Açu dam area, besides field measurements of the directions of the shear zones, we also used measurements of the direction of alignments (traces of foliations and shear zones) using these SLAR images were carried out. drainage channel segments. The location of most computed lineaments is fairly consistent with that of the ductile fabric in the area. The SLAR image in and the lineaments derived from aligned topographic features, which are associated with the ductile Precambrian fabric in, indicate that the regional foliation and shear zones are northeast-southwest oriented $\left(\mathrm{N} 40^{\circ} \mathrm{E}\right)$.

In the João Câmara area, the main direction of the shear zones is taken from literature: the Picuí-João Câmara Shear Zone (PJCSZ) has a N-S to N-NE trend, dipping toward the west, and displays dextral transcurrent kinematics [Vauchez et al., 1995; Coriolano et al., 1997] (Figure 2).

Generally, shear wave splitting is difficult to identify on recorded seismograms. This is partially due to the $S$ arrival, which is complicated by the effects of attenuation, scattering, and near-surface velocity structure. In addition, it is widely known that shear waves can suffer from interference and conversions at a free surface and may lead to a misinterpretation of an S-to-P conversion as being the first pair of split shear waves, especially beyond the critical angle, $\mathrm{i}_{\mathrm{c}}=\sin ^{-1}\left(\mathrm{~V}_{\mathrm{S}} / \mathrm{V}_{\mathrm{P}}\right)$ [Evans, 1984]. It follows that in Precambrian crystalline rocks in intraplate areas such as those in northeastern Brazil, the seismic structure is not complicated significantly by sedimentary structures or extensive recent faulting. Signals may then exhibit high signal-to-noise ratio, very simple waveforms and impulsive $P$ and $S$ arrivals such as those in Figures 3 and 4. The low attenuation and the near-uniform velocity field in such a Precambrian shield provide high signal-to-noise ratio and very good $P$ and $S$ wave observations. In our data set, we decided to include observations with an incident angle of up to $45^{\circ}$ as predicted using the halfspace model. This decision was based on the observation of waveforms, which showed that seismograms with emergence angles of up to $45^{\circ}$ were indeed emerging at an angle subcritical to reflected $P$. Therefore the emergent angle is somewhat less than that predicted by the half-space model because of a velocity gradient near the surface, which is not apparent from the hypocentral location error analysis. For the shear wave splitting analysis, the horizontal seismograms were rotated into the radial and transverse components with respect to the incoming ray. The horizontal components are then rotated again into the polarization direction of the first shear wave and the direction normal to it; the first of these components then contains only the first split shear wave, and the other component is dominated by the second split shear wave. Results from this procedure are shown for two stations: one in the João Câmara and another one in the Açu dam area (Figures 3 and 4). The events were displayed together with polarization diagrams to facilitate the picking of the fast and slow shear waves, whose onsets were manually read from the seismograms. The polarization direction of the first arrival in the horizontal plane is that of the fast split shear wave, and is determined from the horizontal polarization diagrams (which contain most of the shear wave energy), also shown in Figures 3 and 4. For shear waves at nearvertical incidence, the particle motion immediately following the onset of the fast split shear wave is usually sufficiently linear for the polarization direction to be identified. The arrival of the second split $S$ wave (indicated by an arrow in Figures 3 and 4) is, in general, characterized by an abrupt change of particle motion, giving rise to a cruciform pattern on the particle motion diagram.

\section{Results}

We now compare the observed polarization direction at each station with the trend of these shear zones in João Câmara and Açu dam areas.

In the João Câmara area, for comparison purposes, the polarization rose diagrams of the direction of polarization of the fastest split shear-wave have been plotted in Figure 2. They show that the orientation of the fast split shear wave follows closely the trend of the PJCSZ. The directions of the split shear wave agree with the N-S to NNE trend of the PJCSZ measured by Coriolano et al. [1997]. We therefore conclude that, by contrast with the EDA interpretation, this alternative is highly consistent with both seismological and geological observations.

In the Açu area, the fast $S$ wave is polarized in a plane parallel to the orientation of the Precambrian fabric. This is also confirmed by the comparison between the direction of polarization of the split $S$ waves and fabric orientation, presented as rose diagrams (Figure 6). The split $\mathrm{S}$ wave orientations in Açu dam area are depicted in Figure $6 \mathrm{a}$. The lineaments were divided into units, each one corresponding to a feature about $100 \mathrm{~m}$ long in the field. This analysis has yielded more than 5300 lineament units, the orientations of which are presented in Figure $6 \mathrm{~b}$. The striking clustering of these lineaments in the rose diagram conforms to the direction of polarization of the split shear wave data.

Our result suggests that the Precambrian ductile fabric is indeed controlling the seismic anisot-ropy in the region and is consistent with several other shear wave splitting observations throughout the world [Gledhill, 1991; Brocher and Christensen, 1990; Ruzek et al., 2003]. This implies also that the hypothesis of Crampin et al. [1984] on EDA cannot account for all examples of crustal anisotropy and that other mechanisms should be examined to explain the observed polarization direction.

\section{Discussion and conclusion}

The use of a network of eight three-component, digital seismographs in an area with a very simple velocity 
structure in the two areas analysed in NE Brazil, led to excellent location of earthquakes. With such high-quality data set, the analysis of shear wave splitting was facilitated because the seismic structure is not complicated significantly by sedimentary structures or extensive recent faulting. The low-attenuation and the near-uniform velocity field in such a Precambrian shield provided high signal-to-noise ratio and very good $\mathrm{P}$ and $\mathrm{S}$ wave observations.

For the João Câmara area, the consistency of the observed polarization directions of the first split shear wave in all the six stations in this study is very high. The direction of polarizations at the seismographic stations are very close to $\mathrm{N}-\mathrm{S}$ and NE-SW polarizations (Figure $X X X)$, which are the directions of the foliations observed in the shear zone in the area. If the observed anisotropy was caused by EDA, one would expect an E-W direction for the fast split shear wave. In our observations, we show that the anisotropy is consistent with the tectonic structure (foliation, lineation) of the region, and not with anisotropy of stress-aligned fluid-filled cracks. Here, the maximum horizontal compressive stress direction is almost perpendicular to the geological structures in the region, providing maximum differentiation between the two mechanisms.

In the Açu dam area seismograms with very clear shear wave splitting were also analysed. The majority of the shear wave splitting observations indicated that the direction of the fastest shear wave polarization plane is $\mathrm{N} 40^{\circ} \mathrm{E}$. SLAR imagery and field measurements in the dam area revealed that the direction of the ductile Precambrian fabric is also $\mathrm{N} 40^{\circ} \mathrm{E}$. If EDA or abnormally high pore fluid pressures near the surfaces, causing a proposed 90 flip mechanism, were to occur, the direction of the fastest shear wave polarization plane would be either east-west or north-south oriented, respectively. However, the consistency of the seismic and geological data indicates that if these two phenomena occur in the study area, their effects are minor.

From the analysis and interpretation of the seismic anisotropy data in two high quality datasets in NE Brazil, ductile Precambrian fabric analysis on SLAR imagery and in the field, it can be concluded that the seismic anisotropy is consistent with this fabric in the region, and not with anisotropy of stress-aligned fluid-filled cracks, or abnormally high pore fluid pressures.

\section{Acknowledgements}

The authors want to thank CNPq.

\section{References}

Angerer, E., S. Crampin, X.-Y. Li, and T. L. Davis (2002), Processing, modelling and predicting time-lapse effects of overpressured fluid-injection in a fractured reservoir, Geophys. J. Int., 149, 267- 280.

Brocher, T. M., and N. I. Christensen (1990), Seismic anisotropy due to preferred mineral orientation observed in the shallow crust in southern Alaska, Geology, 18, 737-740.
Cassidy, J. F., and M. G. Bostock (1996), Shear-wave splitting above the subducting Juan de Fuca plate, Geophys. Res. Lett., 23(9), 941- 944.

Coriolano, A. C. F., E. F. Jardim de Sá, P. A. Cowie, and C. A. Amaral, Estruturas frágeis no substrato de região de João Câmara (RN): Correlação com a Falha Sísmica de Samambaia? (in Portugese), in XVI Simpósio de Geologia do Nordeste, Fortaleza, CE, in Portuguese, pp. 325-329, 1997.

Crampin, S., R. Evans, and B. K. Atkinson, Earthquake prediction: A new physical basis, Geophys. J. R. Astron. Soc., 76, 147- 156, 1984.

Crampin, S. (1987), Geological and industrial implications of extensive-dilatancy anisotropy, Nature, 328(6130), 491- 496 .

Crampin, S., and J. H. Lovell (1991), A decade of shearwave splitting in the Earth's crust: What does it mean? what use can we make of it? and what should we do next?, Geophys. J. Int., 107, 387-407.

Crampin, S., and S. Zatsepin (1997), Modelling the compliance of crustal rock: II, Response to temporal changes before earthquakes, Geophys. J. Int., 129, 495506.

Crampin, S., T. Volti, S. Chastin, A. Gudmundsson, and R. Stefa'nsson (2002), Indication of high pore-fluid pressure in a seismically active fault zone, Geophys. J. Int., 151, F1-F5.

do Nascimento, A. F., R. G. Pearce, and M. K. Takeya (2002), Local shear-wave observations in João Câmara, northeastern Brazil, J. Geophys. Res., 107(B10), 2232 doi:10.1029/2001JB000560.

do Nascimento, A. F., P. A. Cowie, R. J. Lunn, and R. G. Pearce (2004b), Spatio-temporal evolution of induced seismicity at $A c, u$ reservoir, NE Brazil, Geophys. J. Int., 158, 1041 - 1052, doi:0.1111/j.1365-246X. 2004.02351.x.

Evans, R. (1984), Effects of the free surface on shear wave trains, Geophys. J. R. Astron. Soc., 76, 165-172.

Ferreira, J. M., R. T. Oliveira, M. K. Takeya, and M. Assumpc, a o (1998), Superposition of local and regional stresses in northeast Brazil: Evidence from focal mechanism around the Potiguar marginal basin, Geophys. J. Int., 134, 341-355.

Gledhill, K. R. (1991), Evidence for shallow and pervasive seismic anisot-ropy in the Wellington region, J. Geophys. Res., 96, 21,503-21,516.

Lee, W. H. K., and J. C. Lahr, HYPO71 (revised): A computer program for determining hypocenter and 
magnitude and first motion pattern of local earthquakes, Open File Rep. 75-311, U. S. Geol. Surv., 1975.

Ruzek, B., V. Vravrycuk, P. Hrubcova, J. Zednik, and CELEBRATION Working Group (2003), Crustal anisotropy in the Bohemian Massif, Czech Republic: Observations based on Central European Lithospheric experiment based on refraction (CELEBRATION) 2000, J. Geophys. Res., 2392, doi:10.1029/2002JB002242.

Savage, M. K., W. A. Pepin, and U. R. Vetter (1990), Shear wave anisot-ropy and stress direction in and near Long Valley caldera, California, 1979- 1988, J. Geophys. Res., 95, 11,165-11,177.

Takeya, M. K., High precision studies of an intraplate earthquake sequence in northeast Brazil, unpublished Ph.D. thesis, Univ. of Edinburgh, Edinburgh, 1992.

Vauchez, A., S. Neves, R. Caby, M. Corsini, M. EgydioSilva, M. Arthaud, and V. Amaro, The Borborema shear zone system, NE Brazil, J. South Am. Earth Sci., 8, 247266, 1995.

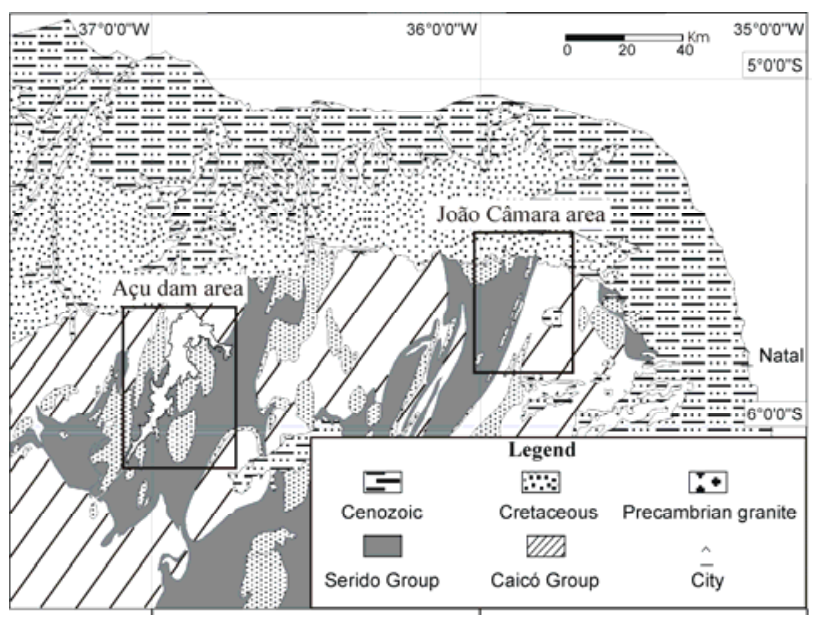

Figure 1: simplified geological map of the studied areas.

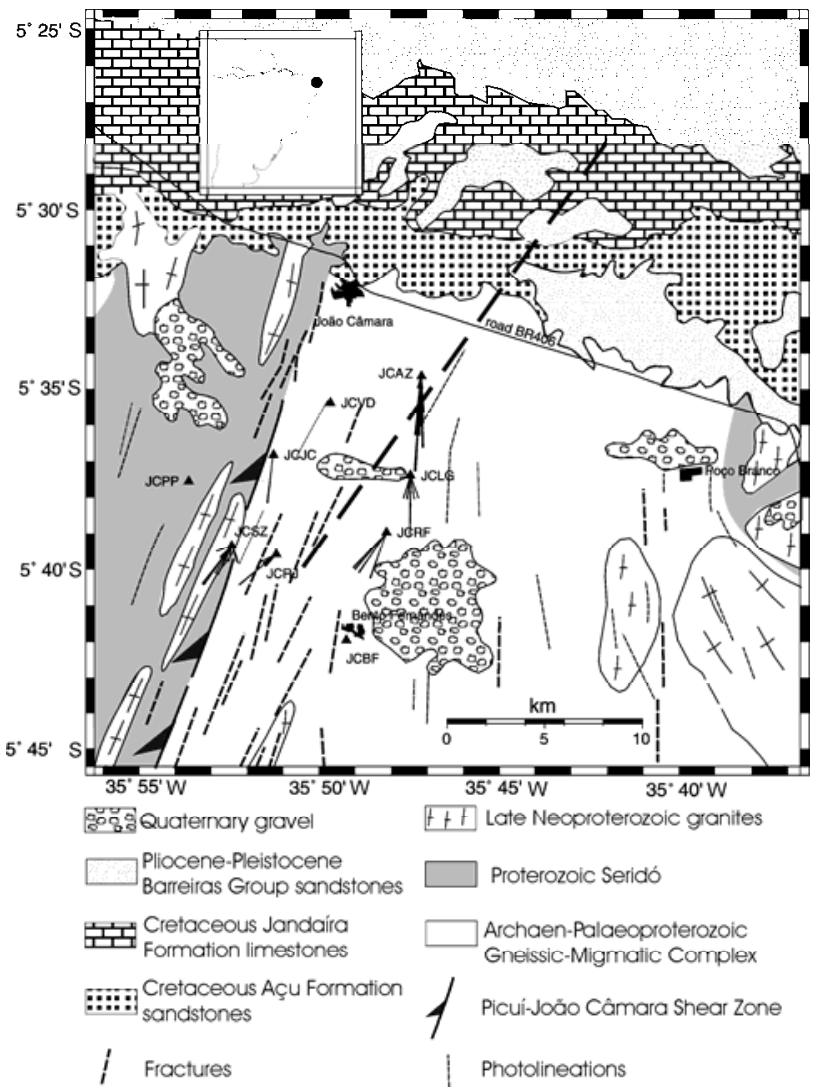

Figure 2: The João Câmara area, showing the locations of the digital network. Also shown is the summary geological information and other features referred to in the text. Rose diagrams of the polarization directions of shear wave first arrivals are also shown for each station. Long-dashed line shows the approximate location of the Samambaia fault, which has been inferred from seismicity alone 
(a)

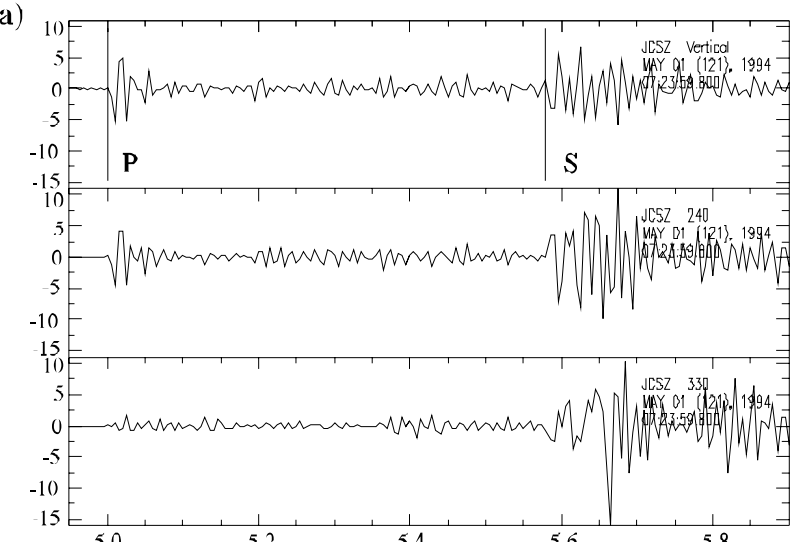

(b)

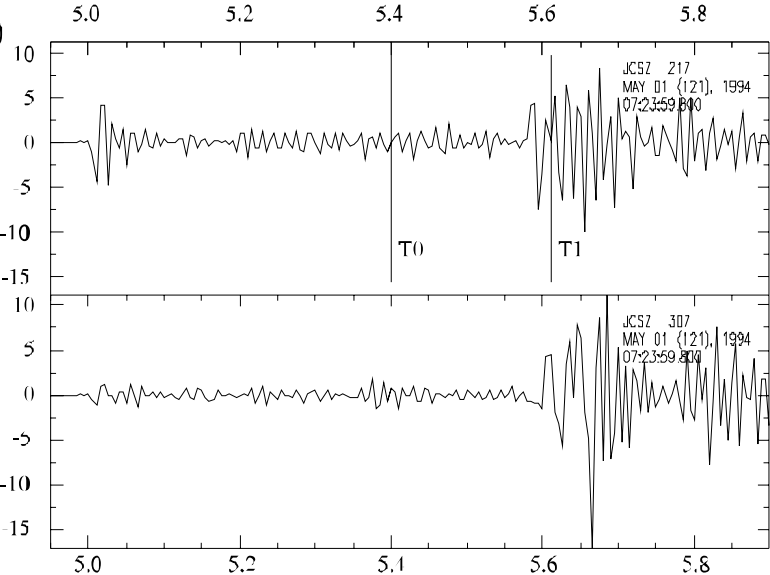

(c)

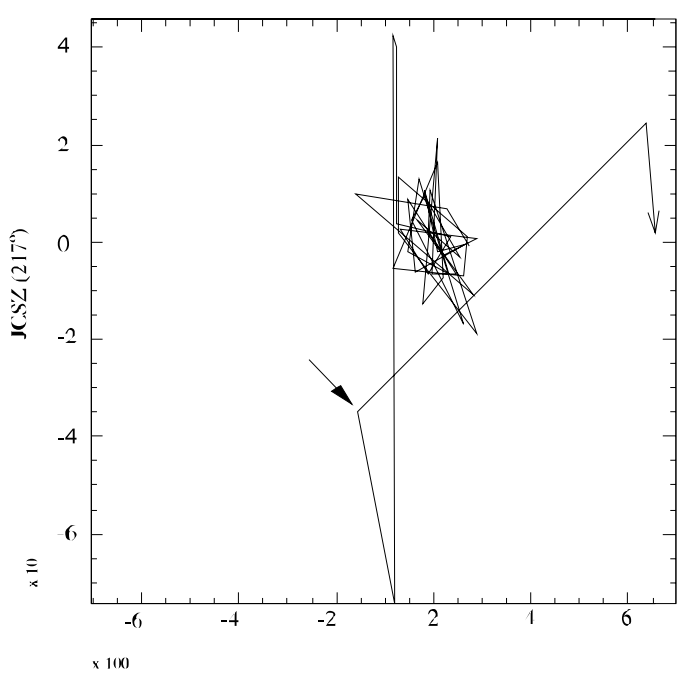

Figure 3. Typical example of shear wave splitting at station JCSZ of the digital network in João Câmara. (a) The vertical component followed by the horizontal components rotated to the radial and transverse directions. (b) the horizontal components rotated to the fast and slow S-wave polarization directions. The azimuth of each horizontal-component seismogram is shown top-right next to the station code. The time marks "T0" and "T1" on the fast component denote the time interval corresponding to the polarization diagram shown in (c), on which the arrival of the second split shear wave is indicated by a filled arrow and that of the particle motion by an open arrow. a)

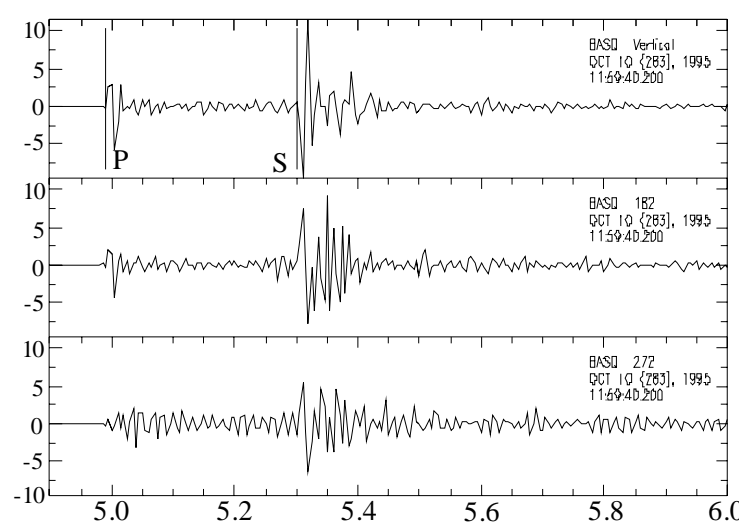

b)

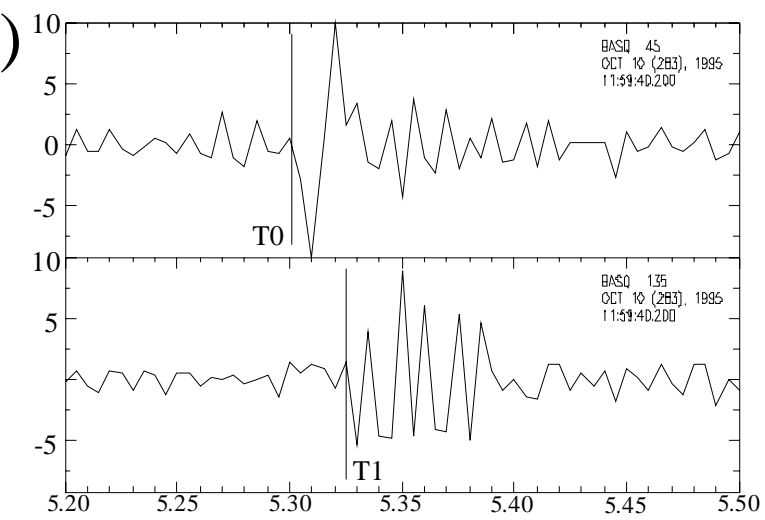

c)

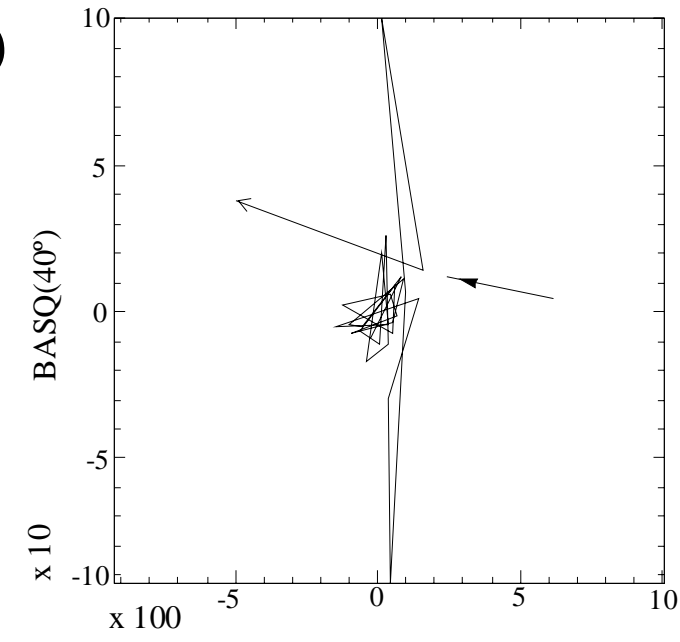

Figure 4. Typical example of shear wave splitting at a station of the digital network in Açu dam area. The same applies for this data. 
a)

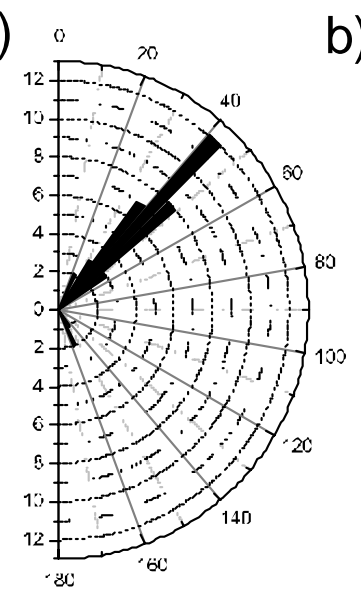

b)

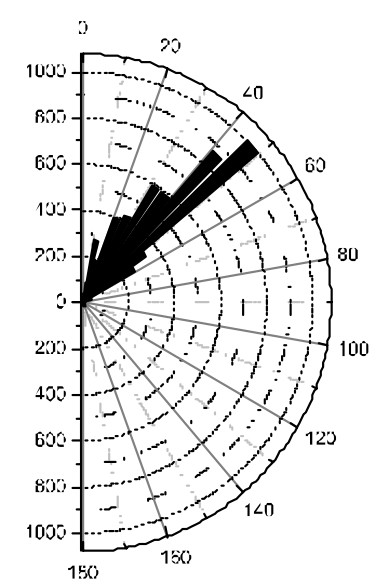

Figure 5. Rose diagrams of (a) directions of polarization of the split shear wave and (b) lineaments derived from SLAR imagery. 